\title{
PRESENÇA DO TÓPICO XERODERMA PIGMENTOSO EM ARTIGOS CIENTÍFICOS PUBLICADOS ENTRE 2003 E 2018
}

\author{
ARTIGO ORIGINAL \\ MOREIRA, Danilo José Silva ${ }^{1}$ \\ FONSECA, Juliana Brito da ${ }^{2}$ \\ ROSSI, Karoline ${ }^{3}$ \\ VASCONCELOS, Suzana dos Santos ${ }^{4}$ \\ OLIVEIRA, Vinicius Faustino Lima de ${ }^{5}$ \\ DIAS, Claudio Alberto Gellis de Mattos ${ }^{6}$ \\ OLIVEIRA, Euzébio ${ }^{7}$ \\ DENDASCK, Carla Viana ${ }^{8}$
}

\footnotetext{
${ }^{1}$ Acadêmico de Medicina. Universidade Federal do Amapá (UNIFAP).

${ }^{2}$ Acadêmica de Medicina. Universidade Federal do Amapá (UNIFAP).

${ }^{3}$ Acadêmica de Medicina. Universidade Federal do Amapá (UNIFAP).

${ }^{4}$ Acadêmica de Medicina. Universidade Federal do Amapá (UNIFAP).

${ }^{5}$ Acadêmico de Medicina. Universidade Federal do Amapá (UNIFAP).

${ }^{6}$ Biólogo, Doutor em Teoria e Pesquisa do Comportamento, Professor e pesquisador do Curso de Licenciatura em Química do Instituto de Ensino Básico, Técnico e Tecnológico do Amapá (IFAP).

7 Biólogo, Doutor em Doenças Topicais, Professor e pesquisador do Curso de Educação Física, Universidade Federal do Pará (UFPA).

8 Teóloga, Doutora em Psicanálise, pesquisadora do Centro de Pesquisa e Estudos Avançados (CEPA).
} 
ARAÚJO, Maria Helena Mendonça de ${ }^{9}$

BRITO, Maysa Vasconcelos de ${ }^{10}$

FECURY, Amanda Alves ${ }^{11}$

MOREIRA, Danilo José Silva. Et al. Presença do tópico Xeroderma Pigmentoso em artigos científicos publicados entre 2003 e 2018. Revista Científica Multidisciplinar Núcleo do Conhecimento. Ano 05, Ed. 03, Vol. 11, pp. 127-134. Março de 2020. ISSN: 2448-0959, Link de acesso: https://www.nucleodoconhecimento.com.br/saude/presenca-do-topicoxeroderma

\section{RESUMO}

O Xeroderma pigmentoso (XP) é uma doença genética rara, de caráter autossômico e recessivo, podendo afetar ambos os sexos, independentemente da raça, e com frequência de um caso a cada 250.000 pessoas. Essa doença possui diversos outros sintomas que se apresentam heterogeneamente sobre seus portadores. $O$ objetivo deste artigo foi analisar quantitativamente a presença do tópico Xeroderma pigmentoso em artigos científicos publicados entre 2003 e 2018. Na identificação obteve-se um total de 674 resultados. O seguimento das etapas seguintes permitiu, no final, a seleção de 24 trabalhos. Em relação ao idioma, a maioria dos trabalhos selecionados estavam escritos na língua portuguesa (em torno de 58,33\%), sendo o restante na língua inglesa (em torno de $41,67 \%$ ). As maiores taxas de publicação ocorreram entre 2015 e 2017 (13\%). Os anos de 2007, 2007, 2011, 2014 e 2018

${ }^{9}$ Médica, Mestra em Ensino e Ciências da Saúde, Professora e pesquisadora do Curso de Medicina do Campus Macapá, Universidade Federal do Amapá (UNIFAP). ${ }^{10}$ Biomédica, Doutora em Doenças Topicais, Professora e pesquisadora Faculdade Estácio de Sá, Macapá.

${ }^{11}$ Biomédica, Doutora em Doenças Topicais, Professora e pesquisadora do Curso de Medicina do Campus Macapá, Universidade Federal do Amapá (UNIFAP). 
apresentaram taxas intermediárias (9\%) e as menores taxas (4\%) ocorreram nos anos de 2003, 2008, 2010 e 2012, e 75\% trabalhos foram publicados/apresentados na $2^{\circ}$ década do século XXI, enquanto que os demais (25\%) foram na $1^{\underline{a}}$ década do século XXI. Os achados desse estudo mostraram que há poucos trabalhos científicos sobre $\mathrm{XP}$ pelo fato de ser uma doença rara, o que possivelmente leva a poucos investimentos nessa área, principalmente no que diz respeito a tratamento e medicamentos.

Palavras-chave: Xeroderma Pigmentoso, publicação, genética.

\section{INTRODUÇÃO}

O Xeroderma pigmentoso $(\mathrm{XP})$ é uma doença genética rara, de caráter autossômico e recessivo, podendo afetar ambos os sexos, independentemente da raça, e com frequência de um caso a cada 250.000 pessoas. Suas características clínicas mais comuns são hiperpigmentação difusa, eritema com descamação e aparecimento precoce de tumores - mil vezes mais frequente nesse grupo de indivíduos do que em pessoas que não possuem tal anomalia cromossômica. Em uma escala molecular, as causas dessa patologia são atribuídas a alta sensibilidade das células a luz ultravioleta (UV) e defeitos na reparação do DNA (Deoxyribonucleic Acid) devido a níveis reduzidos de síntese de DNA reparado, este último contribuindo para de neoplasias cutâneas e anomalias oculares (VIANA et al., 2011).

Essa doença possui diversos outros sintomas que se apresentam heterogeneamente sobre seus portadores. Dentre eles, destacam-se: complicações neurológicas (tumores cerebrais, alterações no eletroencefalograma), vermelhidão dos olhos, anormalidades no desenvolvimento e envelhecimento precoce segmentado, epilepsia, surdez neurossensorial, espasticidade, hiporreflexia ou a arreflexia, paralisias (CHAIBUB, 2011).

O XP possui também uma variação polimórfica alta - do ponto de vista genotípico -, havendo 8 tipos, sendo 7 grupos de complementação clássica (XPA, XPB, XPC, XPD, $\mathrm{XPE}, \mathrm{XPF}, \mathrm{XPG}$ ) e 1 a forma variante (XPV). Os pacientes dos grupos XPA, XPB, 
XPD e XPG têm suas manifestações associadas a sintomas neurológicos, sendo a forma mais grave a síndrome de DeSanctis-Cacchione que está ligada ao tipo A. O $\mathrm{XPV}$ resulta em características clínicas similares às de outras formas, porém tem uma menor gravidade e um prognóstico melhor e, consequentemente, uma maior qualidade e expectativa de vida (VIANA et al., 2011).

Mediante a complexidade e raridade do XP, mostra-se importante destacar da literatura os principais aspectos genéticos e clínicos da doença, contribuindo para integrar em uma mesma produção, diversos achados científicos e, consequentemente, atualizar a comunidade científica acerca (SOCIEDADE BRASILEIRA DE DEMARTOLOGIA, 2020).

\section{OBJETIVO}

Analisar quantitativamente a presença do tópico Xeroderma pigmentoso em artigos científicos publicados entre 2003 e 2018.

\section{METODOLOGIA}

Trata-se de uma pesquisa exploratória, descritiva e retrospectiva, com abordagem quantitativa e analítica de artigos sobre a temática Xeroderma pigmentoso (XP).

Os bancos de dados usados foram: Redalyc, Repositório institucional da Universidade Federal de Juiz de Fora, Scielo, Biblioteca Digital Brasileira de Teses e Dissertações, Science Research.com, Lilacs e Pub Med, utilizando as seguintes palavras-chave associadas: Xeroderma - Xeroderma Pigmentoso. Para melhor selecionar os artigos sobre XP, foram utilizados os filtros: Disciplina (Medicina) na base de dados Redalyc e Repositório institucional da Universidade Federal de Juiz de Fora; citável ou não citável (citável) na Scielo; e limitação somente das opções com texto completo disponível no site Science Research.com, e nas demais bases de dados selecionadas para a pesquisa não foram adicionados filtros. 
Os indicadores utilizados para o estudo foram: a abordagem do XP, em relação aos mecanismos genéticos, incidência e formas de tratamento da doença, assim descrevendo sobre as informações existentes como um todo da patologia em questão.

\section{RESULTADOS}

$\mathrm{Na}$ identificação obteve-se um total de 674 resultados. O seguimento das etapas seguintes permitiu, no final, a seleção de 24 trabalhos, os quais variavam entre teses (de mestrado e doutorado), estudos laboratoriais, estudos epidemiológicos e relatos de caso (Figura 1).

Figura 1 - Fluxograma mostrando a quantidade de trabalhos encontrados aplicando a metodologia.

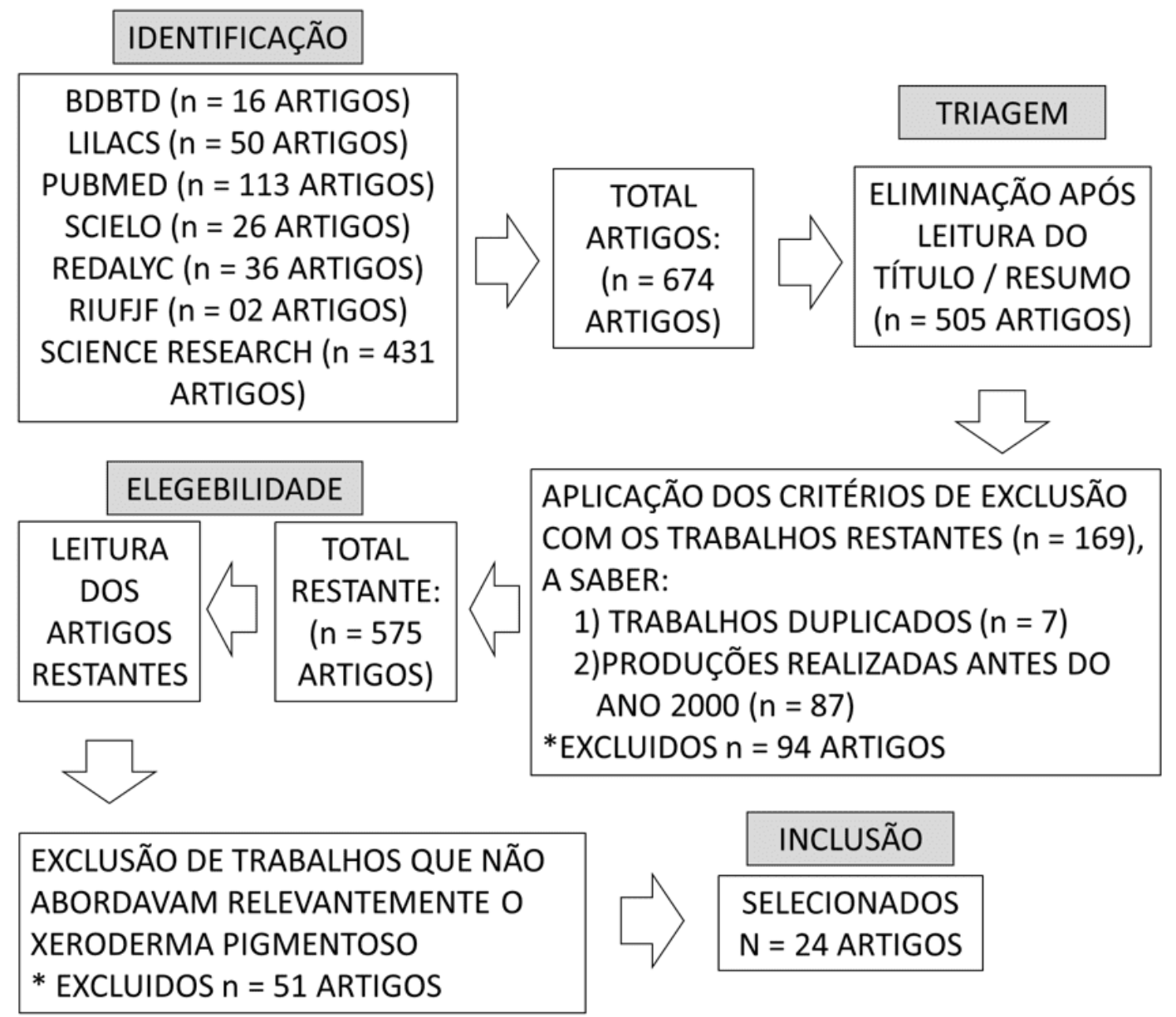


Em relação ao idioma, a maioria dos trabalhos selecionados estavam escritos na língua portuguesa (em torno de $58,33 \%$ ), sendo o restante na língua inglesa (em torno de $41,67 \%$ ) (Figura 2)

Figura 2 Mostra a porcentagem de artigos publicados de acordo com o idioma.

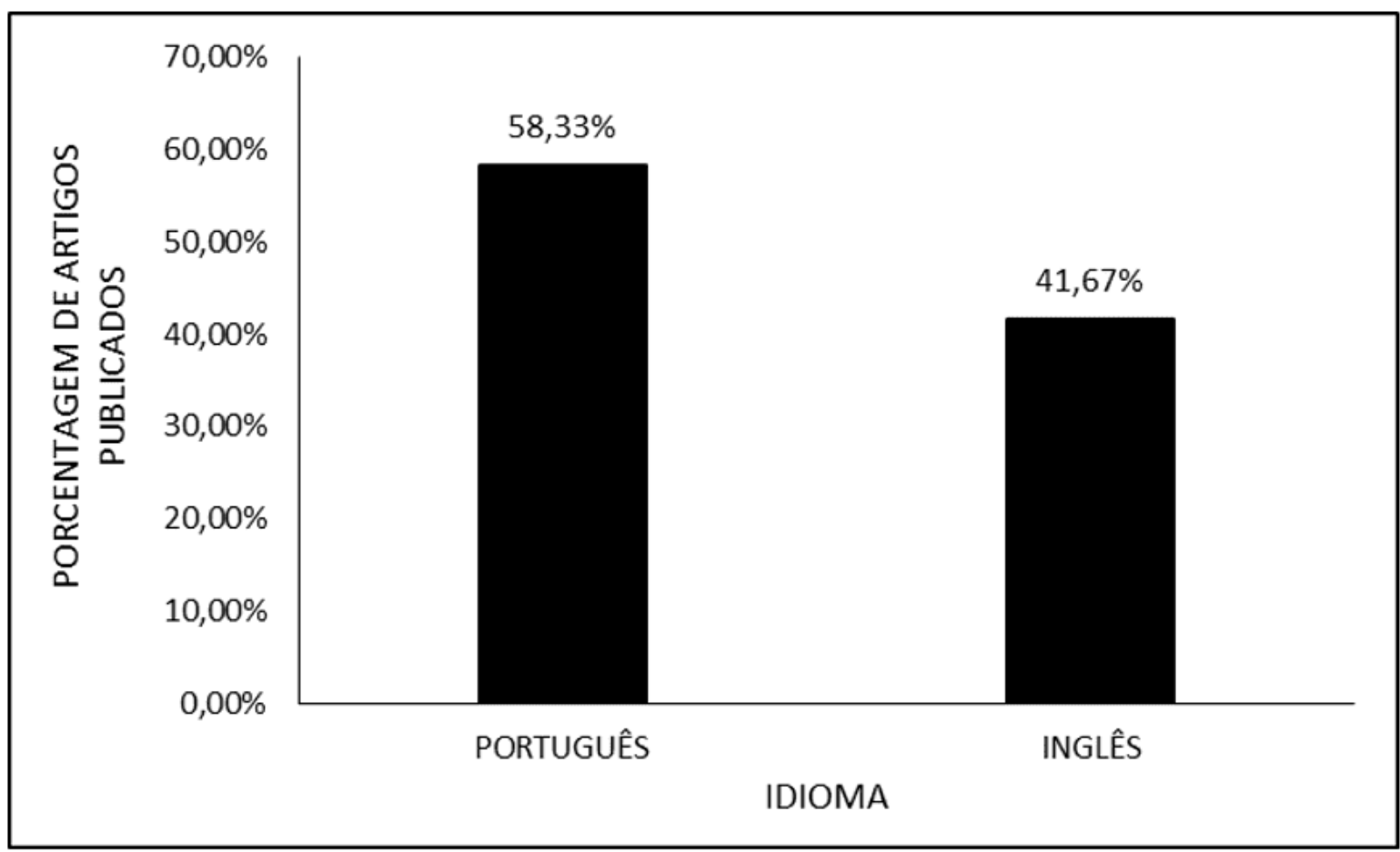

Os dados mostram que em torno de $75 \%$ trabalhos foram publicados/apresentados na $2^{\circ}$ década do século XXI, enquanto os demais $(25 \%)$ foram na $1^{1}$ a década do século XXI (Figura 3). 
Figura 3 Mostra a porcentagem de artigos publicados nas décadas do século vinte e um.

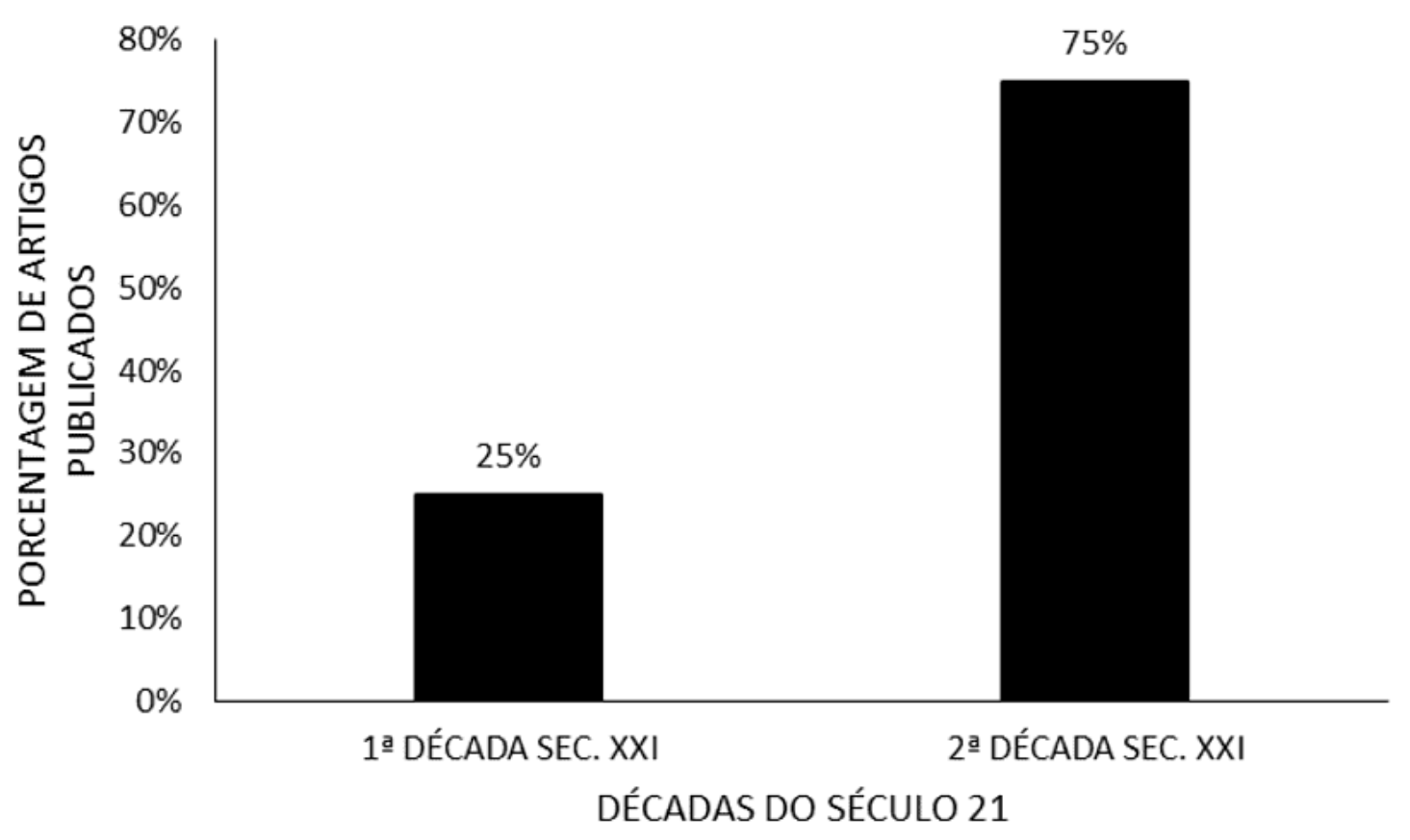

A figura 4 mostra a porcentagem de artigos publicados pelo ano de publicação. Constatou-se que as maiores taxas de publicação ocorreram entre 2015 e 2017 (13\%). Os anos de 2007, 2007, 2011, 2014 e 2018 apresentaram taxas intermediárias (9\%) e as menores taxas (4\%) ocorreram nos anos de 2003, 2008, 2010 e 2012 (Figura 4). 
Figura 4 Mostra a porcentagem de artigos publicados pelo ano de publicação.

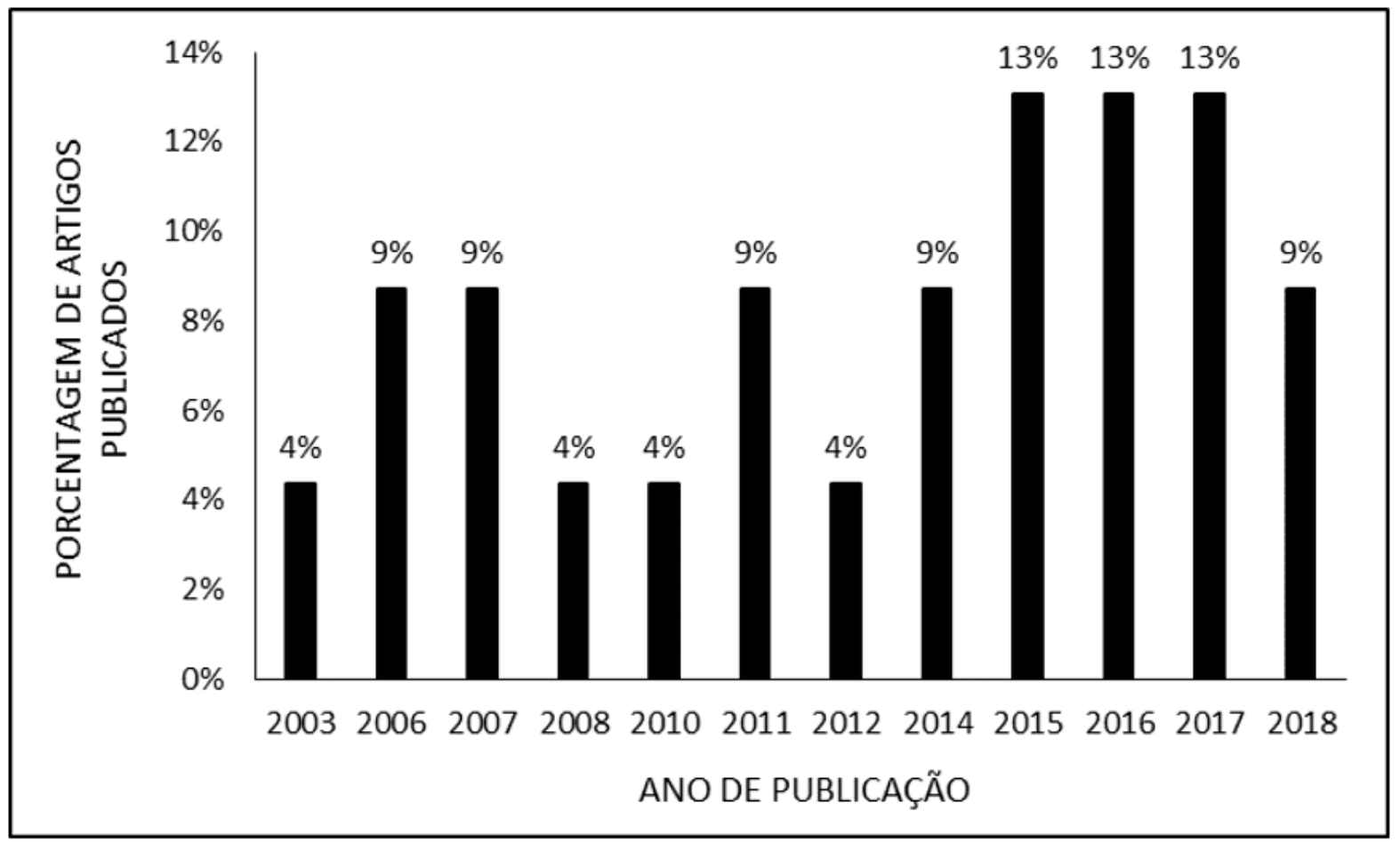

\section{DISCUSSÃO}

Esse número reduzido de trabalhos provavelmente ocorre pela raridade dessa doença que independe de grupos étnicos e cujo principal fator de risco é a consanguinidade, por ser uma doença genética autossômica recessiva. Por exemplo, a frequência do Xeroderma Pigmentoso na Europa e EUA é de 1:1.000.000 e no Japão chega a 1:22.000, possuindo uma prevalência em países do norte da África e do Oriente Médio devido à alta taxa de consanguinidade observada nesses países. Dessa forma, o número reduzido de portadores que estão distribuídos globalmente torna difícil realizar uma pesquisa em larga escala com vários participantes para estudo (DANTAS, 2018).

Os trabalhos selecionados são recentes, todos feitos no século XXI e a maioria feita nos últimos 10 anos. Isso provavelmente se deve ao estudo do aspecto genético da doença. No século XX, discussões acerca de genes e hereditariedade ainda estavam no início. A partir de 2001, com os primeiros esboços da codificação com o advento dos conhecimentos genéticos do genoma humano, doenças que antes não 
conseguíamos atribuir uma causa, passaram a serem mais bem compreendidas (NATIONAL HUMAN GENOME RESEARCH INSTITUTE, 2020). O Xeroderma Pigmentoso sendo uma doença não contagiosa, mas sim, uma patologia hereditária, que se manifesta em virtude da exposição aos raios UV por um defeito no reparo do DNA, depende do embasamento teórico genético (SOCIEDADE BRASILEIRA DE DERMATOLOGIA, 2020).

Outro ponto a ser analisado o grande número trabalhos serem na língua portuguesa, superando aqueles em inglês. Tal fato deve ser elencado com o grande número de casos observados, por exemplo, em Araras, um vilarejo no interior de Goiás onde, devido à alta incidência de consanguinidade, havia uma variedade de casos em relação a idade, manifestação e extensão. Os trabalhos em português eram mais objetivos e completos, trazendo ferramentas para o manejo da doença, como a classificação dos tipos e o desenvolvimento de tratamentos, fornecendo embasamento para o auxílio dessa comunidade (CHAIBUB, 2011).

\section{CONCLUSÃO}

A análise das produções científicas possibilitou reunir estudos sobre o Xeroderma Pigmentoso, os quais estavam em maior quantidade na língua inglesa e portuguesa. O XP tem uma grande sensibilidade a raios UV, o que pode causar várias neoplasias cutâneas e há erro no reparo do DNA. Pode-se concluir que o XP possui 8 tipos que pode variar os sintomas e as sequelas dependendo do tipo de XP.

A maior parte dessas produções abrangem as últimas duas décadas, o que demonstra que as pesquisas sobre esse tema tomaram maior proporção nos últimos anos. Os achados desse estudo mostraram que há poucos trabalhos científicos sobre XP pelo fato de ser uma doença rara, o que possivelmente leva a poucos investimentos nessa área, principalmente no que diz respeito a tratamento e medicamentos. 


\section{REFERÊNCIAS}

ANTUNES, A. A.; ANTUNES, A. P.; SILVA, P. V. A criocirurgia como tratamento alternativo do xeroderma pigmentoso. Revista Odonto Ciência, v. 22, n. 57, p. 228232, set. 2007.

BENSENOUCI, S.; LOUHIBI, L.; VERNEUIL, H.; MAHMOUDI, K.; SAIDI-MEHTAR, N. S. Diagnosis of Xeroderma Pigmentosum Groups $A$ and $C$ by Detection of Two Prevalent Mutations in West Algerian Population: A Rapid Genotyping Tool for the Frequent XPC Mutation. BioMed Research International, v. 2016, n. 2180946 jun. 2016.

CASTRO, L. P. Caracterização genotípica de pacientes brasileiros com deficiência em processos de reparo de DNA. Tese (Doutorado em Biotecnologia) - Universidade de São Paulo. São Paulo, p. 36. 2016.

CHAIBUB, S. C. W. Alta incidência de Xeroderma Pigmentosum em comunidade no interior de Goiás. Surg Cosmet Dermatol, Goiânia, v. 3, n. 1, p. 81-83, jan/mar. 2011.

CLeAVER, J. E.; FEeneY, L.; TANG, J. Y.; TUTTLE, P. Xeroderma Pigmentosum Group $C$ in an Isolated Region of Guatemala. Journal of investigative dermatology, v.127, n. 2, p. 493-496., fev. 2007.

DANTAS, E. B. XERODERMA PIGMENTOSO: RELATO DE CASO. Tese (Trabalho de Conclusão de Curso de Medicina) - Universidade Federal de Sergipe. Lagarto, p. 38, 2018.

DUPUY, A.; VALTON, J.; LEDUC, S.; ARMIER, J.; GALETTO, R.; GOUBLE, A.; LEBUHOTEL, C.; STARY, A.; PAQUES, F.; DUChATEAU, P.; SARASIN, A.; DABOUSSI, F. Targeted Gene Therapy of Xeroderma Pigmentosum Cells Using Meganuclease and TALEN. PLoS One, v. 8, n. 11., páginas, nov. 2013.

FELTES, B. C. Estudo conformacional do complexo proteico DDB2-DDB1 e suas diferentes variantes mutantes na doença Xeroderma Pigmentosum. Tese (Doutorado 
em Biologia celular e molecular) - Universidade Federal do Rio Grande do Sul. Porto Alegre, p. 100. 2017.

HALKUD, R.; SHENOY, A. M.; NAIK, S. M.; CHAVAN, P.; SIDAPPA, K. T.; BISWAS, S. Xeroderma pigmentosum: clinicopathological review of the multiple oculocutaneous malignancies and complications. Indian Journal of Surgical Oncology, v. 5, n. 2, p. 120-124, abr. 2014.

LEITE, R. A. Uso de vetores adenovirais no diagnóstico de portadores de xeroderma pigmentosum e em estudos de reparo de DNA. Tese (Doutorado em microbiologia) Universidade de São Paulo. São Paulo, p. 41, 2008.

LERNER, L. K. Papel das proteínas XPD e DNA polimerase eta nas respostas de células humanas a danos no genoma. Tese (Doutorado em Ciências) - Universidade de São Paulo. São Paulo, p. 201. 2014.

LIU, G.; CHEN, X. DNA Polymerase $\eta$, the Product of the Xeroderma Pigmentosum Variant Gene and a Target of p53, Modulates the DNA Damage Checkpoint and p53 Activation. American Society of Microbiology, v. 26, n. 4, p. 1398-1413, fev. 2006.

MORENO, N. C. Efeitos da luz UVA em células de pacientes com Xeroderma Pigmentosum Variante. Tese (Doutorado em Genética) - Universidade de São Paulo. São Paulo, p. 39. 2017.

MORI, M. P., Novo papel da proteína XPC na regulação dos complexos da cadeia de transporte de elétrons e desequilíbrio redox. Tese (Doutorado em Bioquímica) Universidade de São Paulo. São Paulo, p. 174. 2015.

MOURA, L. M. S. Busca de variantes em sequência de DNA proveniente de pacientes com deficiência em processos de reparo do genoma. Tese (Mestrado em Bioinformática) - Universidade de São Paulo. São Paulo, p. 80. 2015. 
NATIONAL HUMAN GENOME RESEARCH INSTITUTE. NHGRI History and Timeline of Events. Disponível em:< https://www.genome.gov/about-nhgri/BriefHistory-Timeline\#three>. Acesso em: 25 mar. 2020.

OLIVEIRA, C. R. D; ELIAS, L.; BARROS, A. C. M; CONCEIÇÃO, D. B. Anestesia em Paciente com Xeroderma Pigmentoso. Relato de Caso. Revista Brasileira de Anestesiologia, Florianópolis, v. 53, n. 1, p. 46-51, jan/fev. 2003.

ORTEGA-RECALDE, O. O.; VERGARA, J. I.; FONSECA, D. J.; RIOS, X.; MOSQUERA, H.; BERMUDEZ, O. M.; MEDINA, C. L.; VARGAS, C. I.; PALLARES, A. E.; RESTREPO, C. M.; LAISSUE. P. Whole-Exome Sequencing Enables Rapid Determination of Xeroderma Pigmentosum Molecular Etiology. Plos One, v. 8, n. 6, jun. 2013.

PUUMALAINEN, M. R.; RUTHERMANN, P.; MIN, J. H.; NAEGELI, H. Xeroderma pigmentosum group $\mathrm{C}$ sensor: unprecedented recognition strategy and tight spatiotemporal regulation. Cellular and Molecular Life Sciences, v. 73, 547-566, out. 2016.

RIBEIRO, M. G.; ZUNTA, G. L.; SANTOS, J. S.; MORAES, A. M.; LIMA, C. S. P.; ORTEGA, M. M. Clinical features related to xeroderma pigmentosum in a Brazilian patient diagnosed at advanced age. Dove Medical Press, v. 11, p. 89-92, ago. 2018.

SANTIAGO, S. P. Estudo de polimorfismos de genes de reparo do DNA em lesão de fita simples e sua associação com aspectos clínicos e laboratoriais de portadores de síndrome mielodisplásica. Tese (Mestrado em ciências médicas) - Universidade Federal do Ceará. Fortaleza, p. 111. 2015.

SOCIEDADE BRASILEIRA DE DERMATOLOGIA. Xeroderma pigmentoso: O que é?. Disponível em:<https://www.sbd.org.br/dermatologia/pele/doencas-eproblemas/xeroderma-pigmentoso/55/>. Acesso em: 25 mar. 2020. 
SOLTYS, D. T. Análise da natureza genotípica de pacientes Xeroderma pigmentosum Brasileiros. Tese (Doutorado em Microbiologia) - Universidade de São Paulo. São Paulo, p. 43. 2010.

UEDA, T.; KANDA, F.; AOYAMA, N.; FUJII, M.; NISHIGORI, C.; TODA, T. Neuroimaging features of xeroderma pigmentosum group A. Brain and Behavior, v. 2, n. 1, p. 1-5, jan. 2012.

VIANA, F. O.; CAVALEIRO, L. H. S; CARNEIRO, C. M. M. O.; BITTENCOURT, M. J. S.; BARROS, R. S.; FONSECA, D. M. Você conhece esta síndrome? Síndrome de DeSanctisCacchione: relato de caso com esquizencefalia. Anais Brasileiros de Dermatologia, v. 86, n. 5, p.1029-38, 2011.

ZAMARRÓN, A.; GARCÍA, M.; RÍO, M.; LARCHER, F.; JUARRANZ, A. Effects of photodynamic therapy on dermal fibroblasts from xeroderma pigmentosum and GorlinGoltz syndrome patients. Oncotarget, v. 8, n. 44, p. 77385-77399, set. 2017.

Enviado: Março, 2020.

Aprovado: Março, 2020. 